\title{
Esophageal foreign body causing direct aortic injury
}

\author{
ECS Lam M D FRCPC ${ }^{1}$, JA Brown MD FRCPC ${ }^{2}$, JS W hittaker M D FRCPC 3
}

ECS Lam, JA Brown, JS W hittaker. E sophageal foreign body causing direct aortic injury. Can J G astroenterol 2003;17(2):115-117.

Foreign bodies in the esophagus are uncommon causes of esophageal perforation. M any nonperforating cases are successfully managed by flexible gastroscopy. However, complicated foreign bodies such as those that result in esophageal perforation and vascular injury are best managed surgically. G astroscopy remains the primary method of diagnosis. A case of a 59-year-old woman who developed retrosternal and intrascapular pain, odynophagia and hematemesis after eating fish is reported. Flexible gastroscopy showed arterial bleeding from the midthoracic esophagus. Computed tomography scan localized a $3 \mathrm{~cm}$ fish bone perforating the esophagus with surrounding hematoma. A $n$ aortogram did not reveal an actively bleeding aortoesophageal fistula. The fish bone was surgically removed and the patient recovered with no postoperative complications. This case illustrates the importance of early consideration for surgical intervention when confronted with a brisk arterial bleed from the esophagus with suggestive history of foreign body ingestion.

Key W ords: E sophageal perforation; Foreign body; $H$ ematemesis

E sophageal perforation and its complications have been well $E_{\text {documented in the literature (1-3). Documented etiologies }}$ include tumours, iatrogenic causes, trauma and foreign body ingestion. Foreign body ingestion is an uncommon cause of esophageal perforation but the complications associated with a prolonged impaction can result in considerable morbidity and mortality. A Ithough there have been many cases reported of aortoesophageal fistulae following foreign body ingestion, little has been published about direct aortic injury from a foreign body. Because esophageal perforation and vascular injury usually present as hematemesis or melena, gastroenterologists should be aware of this diagnostic possibility. We present a case of esophageal perforation associated with direct vascular injury related to an aortic puncture caused by a fish bone.

\section{CASE PRESEN TATION}

A previously healthy 59 -year-old woman presented to a local infirmary with a $3 \mathrm{~h}$ history of retrosternal chest pain. The pain began immediately after eating a meal of fish. The restrosternal chest pain was pleuritic in nature. The patient had odynophagia. She was treated conservatively with antacids and dis-

\section{U n corps étranger dans l'œsophage provoque une lésion aortique directe}

La présence de corps étrangers dans I'œsophage est une cause rare de perforation œsophagienne. De nombreux cas sans perforation sont traités avec succès par gastrofibroscopie. Cependant, des corps étrangers complexes comme ceux qui résultent en une perforation œsophagienne et en une lésion vasculaire sont mieux pris en charge par voie opératoire. La gastroscopie demeure le principal mode diagnostique. $0 \mathrm{n}$ présente le cas d'une femme de 59 ans qui a développé des douleurs rétrosternales et interscapulaires, une odynophagie et une hématémèse après avoir mangé du poisson. La gastrofibroscopie a démontré la présence d'un saignement artériel dans l'œsophage thoracique médian. La tomodensitométrie a permis de repérer une arête de poisson de $3 \mathrm{~cm}$ perforant l'œsophage et entourée d'un hématome. Un aortogramme n'a pas révélé la présence d'une fistule aortœsophagienne avec saignement actif. L'arête de poisson a été retirée par voie chirurgicale, et la patiente s'est remise sans complications postopératoires. C e cas illustre l'importance d'une éval uation précoce d'intervention chirurgicale face à un saignement artériel intense dans I'œsophage et d'antécédents présumant l'ingestion d'un corps étranger.

charged home. She returned two days later because the pain persisted and began to radiate to the intrascapular region. She became diaphoretic and pale. There were no complaints of nausea or vomiting. The patient was then seen at a peripheral hospital where the possibility of aortic dissection was considered. She was transferred to this hospital for further investigation.

The patient was seen by the cardiovascular surgery service during which she had two episodes of fresh hematemesis. Her hemoglobin was $118 \mathrm{~g} / \mathrm{L}$ at the peripheral hospital and dropped to $100 \mathrm{~g} / \mathrm{L}$ after the hematemesis. There was no antecedent history of melena or gastrointestinal bleeding in the past. She was a lifelong nonsmoker, did not use alcohol and there was no history of acetylsalicylic acid or nonsteroidal anti-inflammatory drug use. $H$ er hepatitis $B$ and $C$ status was unknown. There was no history of peptic ulcer disease.

On physical examination, she was pale, diaphoretic and drowsy. The blood pressure was 102/42 $\mathrm{mmH} g$ with no pulsus paradoxus. The heart rate was 64 beats/min and she was afebrile. $\mathrm{H}$ er peripheral pulses were symmetric. There was no

${ }^{1}$ D epartment of M edicine, U niversity of A lberta, Edmonton, A lberta; D epartments of ${ }^{2}$ Radiology and ${ }^{3} \mathrm{M}$ edicine, St Paul's H ospital, Vancouver, British Columbia

C orrespondence and reprints: Dr Eric CS Lam, D epartment of M edicine, D ivision of G astroenterology, $519 \mathrm{~N}$ ewton Research Building, U niversity of A lberta, Edmonton, A lberta T6G 2C2. Telephone 780-407-8226, fax 780-407-3744, e-mail ericl@ualberta.ca

Received for publication June 10, 2002. A ccepted N ovember 8, 2002 


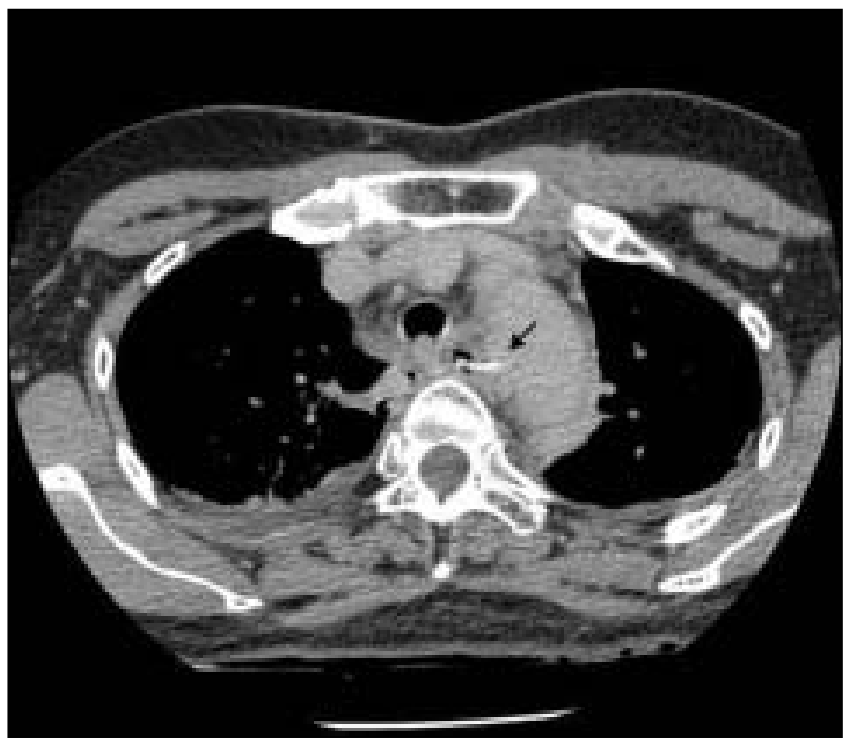

Figure 1) A xial helical computed tomographic image obtained at level of crossing left brachiocephalic vein shows the lateral end of the fish bone abutting the medial wall of the transverse portion of the thoracic aorta (arrow)

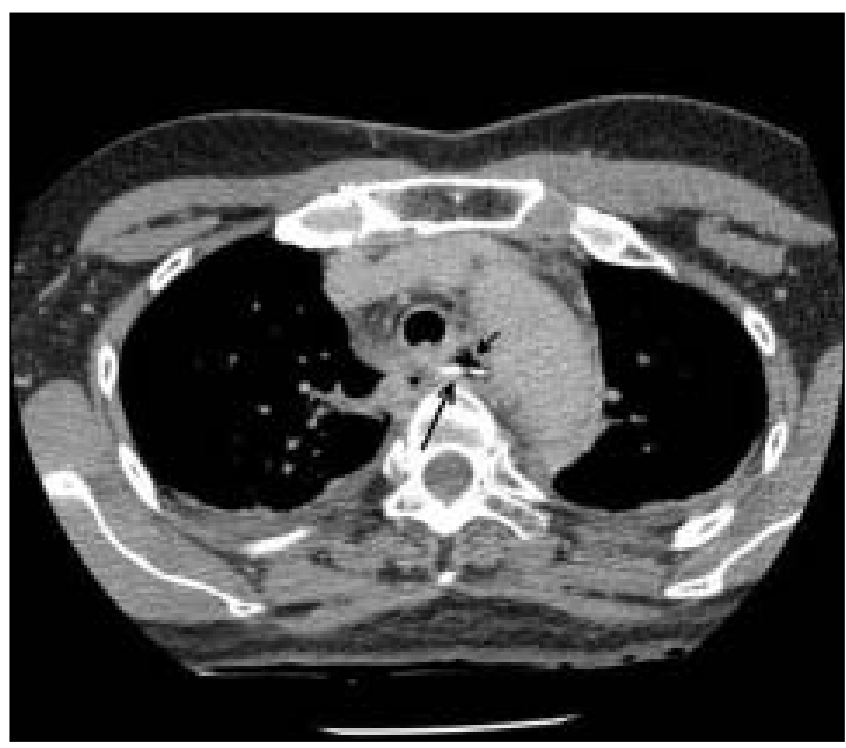

Figure 2) A xial helical computed tomographic image, $1 \mathrm{~mm}$ caudal to the image in Figure 1, shows the main body of the fish bone (large arrow). N ote the extraluminal air (small arrow) compatible with perforation

palpable subcutaneous emphysema. The remainder of the examination was unremarkable.

Laboratory examination revealed a normal platelet count and coagulation status. The electrocardiogram was normal. A chest x-ray did not show a widened mediastinum nor any subcutaneous or mediastinal air.

On endoscopy, a fresh arterial bleed was seen at approximately $20 \mathrm{~cm}$ from the upper alveolar ridge. A fish bone was embedded in the wall of the esophagus. A contrast enhanced computed tomography (CT) examination of the thorax was subsequently performed. The fish bone, measuring approximately $3 \mathrm{~cm}$ in length, was seen lying almost horizontally in

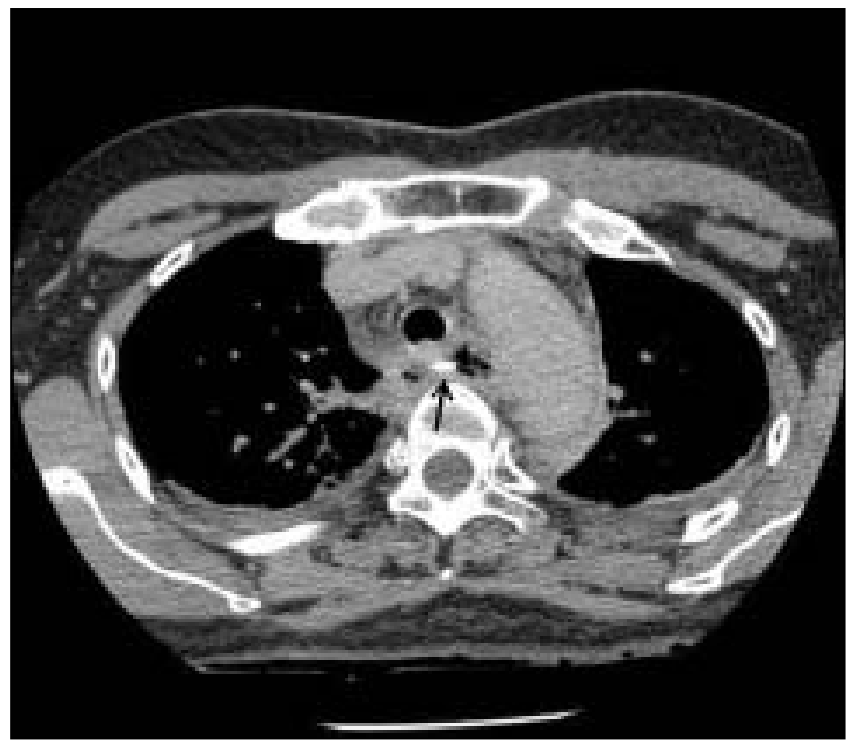

Figure 3) A xial computed tomographic image, $1 \mathrm{~mm}$ caudal to the image in Figure 2, demonstrates the medial end of the fish bone posterior to the trachea (arrow)

the proximal thoracic esophagus at the level of the crossing left brachiocephalic vein. Its medial end was seen posterior to the trachea while its lateral end was seen directly abutting the medial aspect of the transverse portion of the thoracic aorta (Figures 1 and 2). Increased attenuation in the mediastinal fat surrounding the thoracic esophagus was present, as were small locules of extraluminal air compatible with perforation (Figure 3). Small bilateral pleural effusions with accompanying bibasilar atelectasis were also noted. A n aortogram was also performed, which did not show an aortic leak. The patient was resuscitated with three units of packed red blood cells and underwent a right hemithoracotomy the following day.

Intraoperative findings included perforations of the left and right lateral aspects of the midthoracic esophagus by a $3 \mathrm{~cm}$ fish bone. The fish bone was embedded in the right lateral wall of the esophagus, approximately $3 \mathrm{~cm}$ above the azygos vein. A hematoma surrounding the transverse aorta was seen.

Postoperatively, the patient received antibiotics for 10 days, and a follow-up gastrograffin swallow was normal. She was discharged two weeks after presentation. She remained well two months after presentation.

\section{DISCUSSION}

Esophageal perforation occurs in $1 \%$ to $4 \%$ of instances of foreign body ingestion $(1,2)$. These complications carry a considerable morbidity from mediastinitis, paraesophageal abscess, pericarditis, pneumothorax, pyopneumothorax and pneumomediastinum (2). In a series of 511 cases of esophageal perforation, there is a reported mortality of $22 \%(4)$. Foreign body perforation was the etiology of $7 \%$ in that series. This condition, although uncommon, must be recognized in the appropriate clinical context.

Local inflammation results in erosion by the foreign body to adjacent structures. A reas of anatomic constriction have an increased risk of foreign body impaction and are common sites of perforation. The aorta is often involved and there are case 
reports of aortoesophageal fistulae developing over weeks to years (5). A ortoesophageal fistula is a diagnosis that is almost invariably fatal. Sloop and Thompson (6) described the clinical features of this condition. A 'signal hemorrhage' precedes exsanguination, the timing of which is unpredictable. A fistulized tract through inflammatory tissues is thought to be the cause of the exsanguination, but the signal hemorrhage is thought to be due to local arterial bleeding (6). The current case was that of persistent pain and odynophagia for two days before the presentation of the signal hemorrhage. This demonstrates the extreme variability of the time course in vascular injury from foreign body esophageal perforation.

A lthough the bleeding seen on gastroscopy could have been a result of esophageal venous plexus injury, it is more likely that aortic injury had occurred. Bleeding from esophageal perforation most commonly results in intramural hematomas, but focal thickening of the esophageal wall was not seen. There are no case reports of intramural esophageal bleeding resulting in mediastinal hematomas as was seen in this case.

Direct visualization by gastroscopy remains an important method in the diagnosis of esophageal foreign bodies. Many therapeutic gastroscopic manoeuvres are used to disimpact the esophagus (7). We suggest that flexible gastroscopy is contraindicated in a case of established esophageal perforation. Although few case studies exist on flexible gastroscopy in esophageal perforation with subsequent conservative management of mediastinitis (8), it is reasonable to suggest that air insufflation during this procedure would lead to further morbidity. C haracteristics of the suspected foreign body (coins [9], fishbones, needles [10]), duration of foreign body impaction, underlying esophageal disease and clinical presentation with complications are required to assess the probability of esophageal perforation. In the present case, there was no

\section{REFERENCES}

1. Sharland M G, M CC aughan BC. Perforation of the esophagus by a fish bone leading to cardiac tamponade. A nn Thorac Surg 1993;56:969-71.

2. Scher RL, Tegtmeyer CJ, M CLean W C. Vascular injury following foreign body perforation of the esophagus. Review of the literature and report of a case. A nn Otol Rhinol Laryngol 1990;99:698-702.

3. M ok CK, Chiu CS, Cheung H H. Left subclavian arterioesophageal fistula induced by a foreign body. A nn Thorac Surg 1989;47:458-60.

4. Jones W G, G insberg RJ. Esophageal perforation: A continuing challenge. A nn Thorac Surg 1992;53:534-43.

5. Heckstall RL, Hollander JE. A ortoesophageal fistula: Recognition and diagnosis in the emergency department. A nn Emerg M ed 1998;32:502-5

6. Sloop RD, Thompson JC. A orto-esophageal fistula: Report of a case and review of the literature. G astroenterology 1967;53:768-77.

7. Bertoni G, Pacchione D, Sassatelli R, Ricci E, M ortilla M G, Gumina C. A new protector device for safe endoscopic removal of sharp gastroesophageal foreign bodies in infants. J Pediatr G astroenterol N utr 1993;16:393-6.

8. N ozoe T, Kitamura M, A dachi Y, et al. Successful conservative treatment for esophageal perforation by a fish bone associated with objective $\mathrm{x}$-ray evidence that esophageal perforation had occurred before the endoscopy. However, we suggest that if there is radiological evidence, or if clinical suspicion remains high for esophageal perforation, rigid esophagoscopy or CT scanning should be performed.

The role of $C T$ in foreign body esophageal perforation has been documented. A retrospective study of the CT scans of 12 patients with esophageal perforation revealed that extraluminal air was the most useful finding (11). The evaluated features, however, are not pathognomonic for esophageal perforation (12). The role of CT is not to confirm a highly suspicious case of esophageal perforation due to a foreign body but to provide further evidence in atypical cases. In the case presented, the fish bone was easily seen and the surrounding hematoma confirmed the observation that vascular injury was likely.

$\mathrm{N}$ onoperative treatment of esophageal perforation without vascular injury may result in complications such as mediastinitis. Definitive treatment is controversial and some have advocated conservative treatment, even in cases of mediastinitis (8). Novel endoscopic treatments have been attempted, including endoscopic clipping of esophageal perforations (13). Some selective cases have resolved in a nonoperative approach (14) but if there is a question of vascular injury, as with this case, operative management is the best choice (15).

The above case illustrates the importance of a detailed history, physical examination and timely investigations when dealing with a foreign body perforation of the esophagus resulting in vascular injury. In suspected esophageal perforation, C T scan remains the diagnostic modality of choice. If the CT scan does not show evidence of perforation but clinical suspicion remains high, the next diagnostic modality should be rigid esophagoscopy or surgery.

mediastinitis. H epatogastroenterology 1998;45:2190-2.

9. Dahiya M , Denton JS. Esophagoaortic perforation by foreign body (coin) causing sudden death in a 3-year-old child. A m J Forensic Med Pathol 1999;20:1848.

10. M osca S, M anes G, M artino R, et al. Endoscopic management of foreign bodies in the upper gastrointestinal tract: Report on a series of 414 adult patients. Endoscopy 2001;33:692-6.

11. W hite CS, Templeton PA, A ttar S. Esophageal perforation: CT findings. A m J Roentgenol 1993;160:767-70.

12. O oms HW, Coerkamp EG. Esophageal perforation: Role of esophagography and CT. A m J Roentgenol 1994;162:1001-2.

13. Shimamoto C, H irata I, U megaki E, Katsu K. Closure of an esophageal perforation due to fish bone ingestion by endoscopic clip application. Gastrointest Endosc 2000;51:736-9.

14. Cameron JL, Kieffer RF, H endrix TR, M ehigan DG, Baker RR. Selective nonoperative management of contained intrathoracic esophageal disruptions. A nn Thorac Surg 1979;27:404-8.

15. A thanassiadi K, G erazounis M, M etaxas E, Kalantzi N . $M$ anagement of esophageal foreign bodies: A retrospective review of 400 cases. Eur J Cardiothorac Surg 2002;21:653-6. 


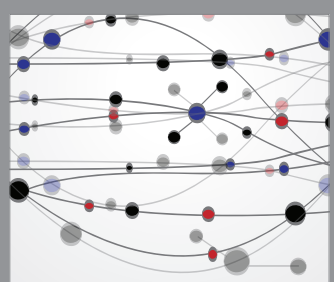

The Scientific World Journal
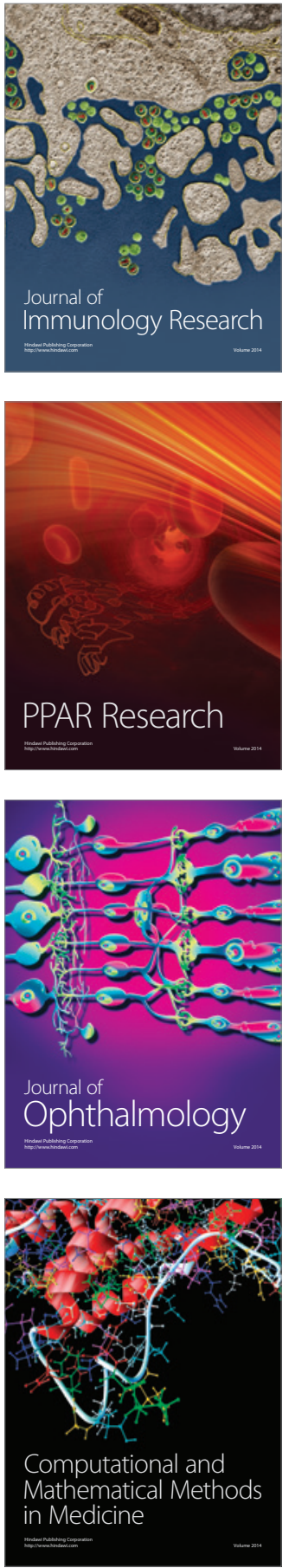

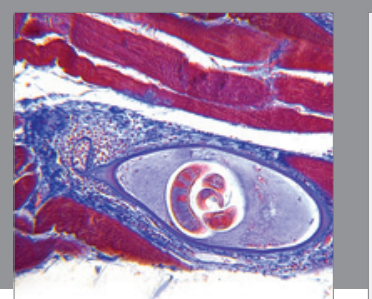

Gastroenterology Research and Practice

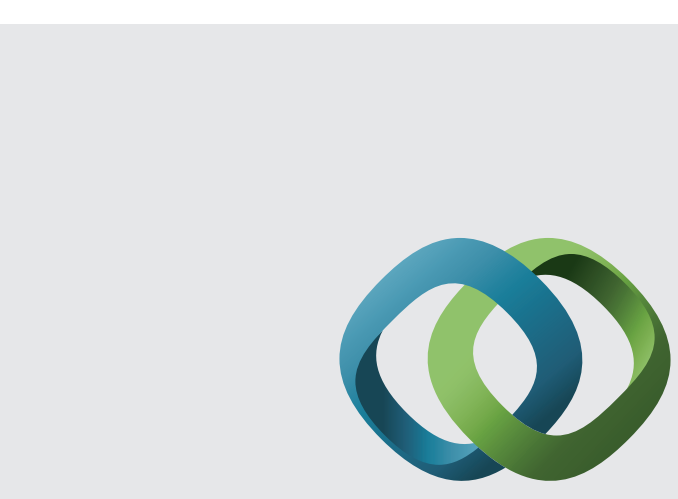

\section{Hindawi}

Submit your manuscripts at

http://www.hindawi.com
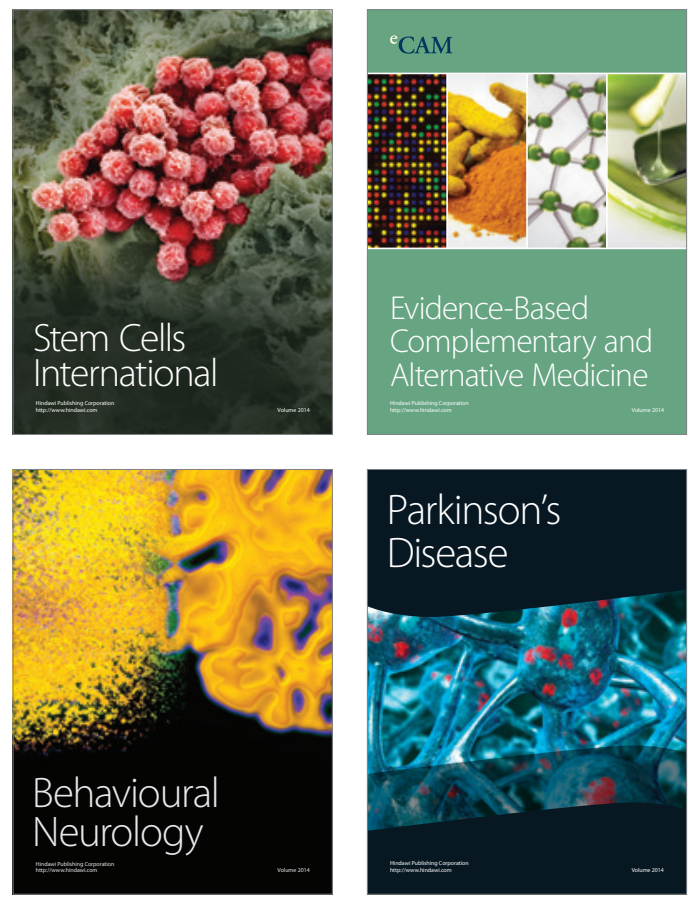
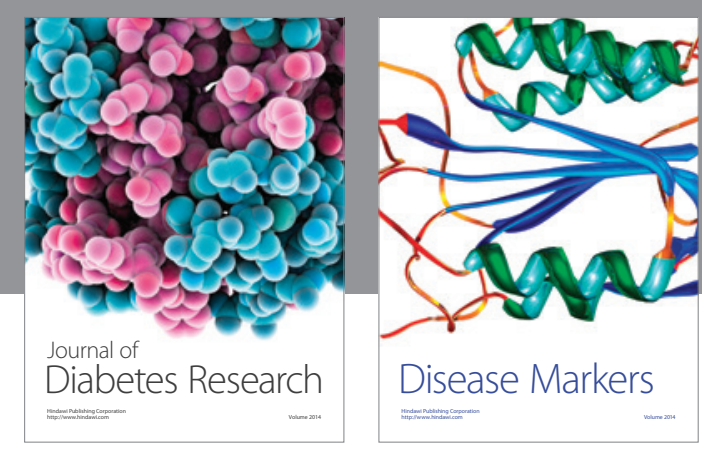

Disease Markers
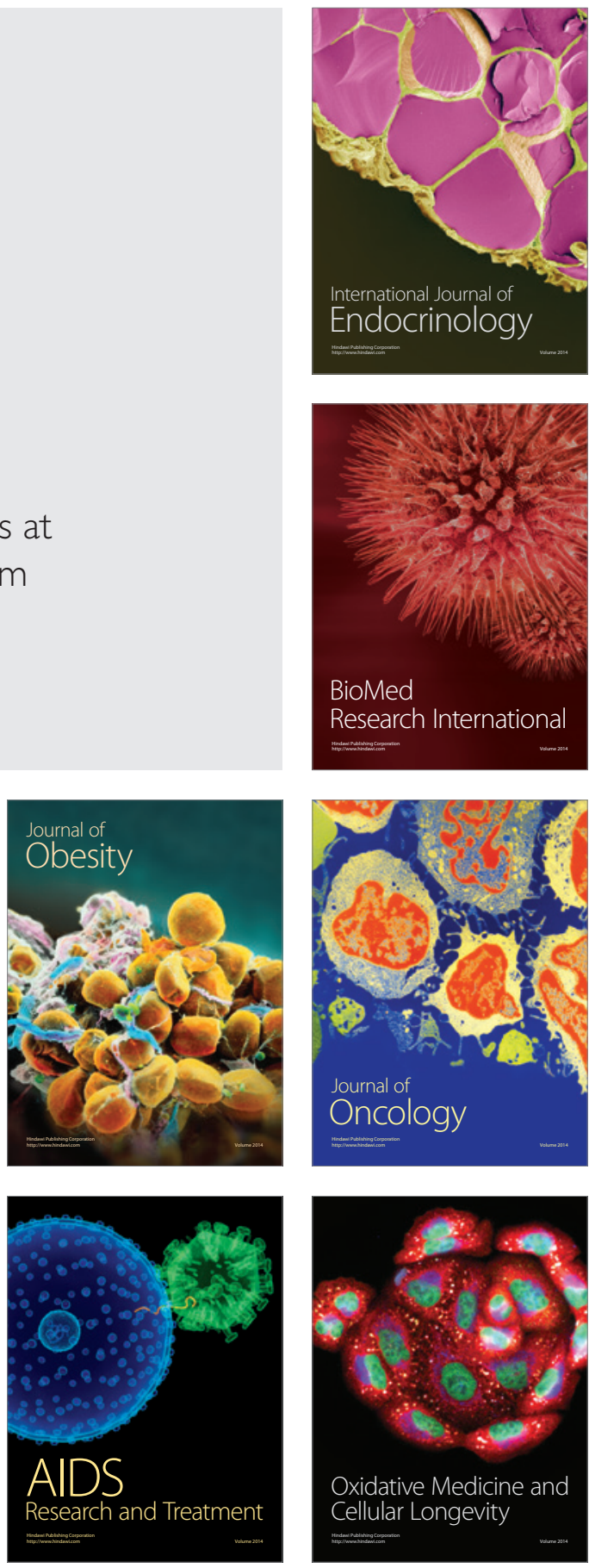